\title{
COMMENT
}

\section{COVID-19 vaccine safety}

\author{
RONALD N. KOSTOFF ${ }^{1}$, MICHAEL B. BRIGGS ${ }^{2}$, ALAN L. PORTER ${ }^{3}$, \\ DEMETRIOS A. SPANDIDOS ${ }^{4}$ and ARISTIDIS TSATSAKIS ${ }^{5}$ \\ ${ }^{1}$ School of Public Policy, Georgia Institute of Technology, Gainesville, VA 20155; \\ ${ }^{2}$ Independent Consultant, Roscommon, MI 48653; ${ }^{3}$ School of Public Policy, Georgia Institute of Technology, \\ Atlanta, GA 30332, USA; ${ }^{4}$ Laboratory of Clinical Virology and ${ }^{5}$ Laboratory of Toxicology, \\ Medical School, University of Crete, 70013 Heraklion, Greece
}

Received September 2, 2020; Accepted September 18, 2020

DOI: $10.3892 / \mathrm{ijmm} .2020 .4733$

\begin{abstract}
In response to the SARS-CoV-2 outbreak, and the resulting COVID-19 pandemic, a global competition to develop an anti-COVID-19 vaccine has ensued. The targeted time frame for initial vaccine deployment is late 2020. The present article examines whether short-term, mid-term, and long-term vaccine safety can be achieved under such an accelerated schedule, given the myriad vaccine-induced mechanisms that have demonstrated adverse effects based on previous clinical trials and laboratory research. It presents scientific evidence of potential pitfalls associated with eliminating critical phase II and III clinical trials, and concludes that there is no substitute currently available for long-term human clinical trials to ensure long-term human safety.
\end{abstract}

\section{Introduction}

The new outbreak of SARS-CoV-2 from December 2019 precipitated a world-wide crisis. Globally, lockdowns of different severity levels were imposed (1). While the number of daily deaths attributable to COVID-19 appears to have decreased substantially by June 2020 , the increasing numbers of 'cases' (positive test results for viral exposure) have raised some concerns regarding the ability of governments and decision-making authorities to reduce viral transmission and subsequent consequences (2-4). Currently, at 10 months following the outbreak, no specific treatment for severe forms of COVID-19 has achieved consensus within the medical

Correspondence to: Dr Ronald N. Kostoff, School of Public Policy, Georgia Institute of Technology, Gainesville, VA 20155, USA

E-mail: rkostoff@gmail.com

Professor Aristidis Tsatsakis, Laboratory of Toxicology, Medical School, University of Crete, 70013 Heraklion, Greece

E-mail: tsatsaka@uoc.gr

Key words: SARS-CoV-2, COVID-19 vaccine, COVID-19 pandemic community, although several potential therapies appear to have produced more or less encouraging results (5-11).

The methods used to contain the spread of the virus have been the traditional social distancing, quarantine, use of disinfectant substances, and wearing of protective face masks (12-14). These measures have adverse consequences, both psychological and economic, and have resulted in substantial disagreement among the medical community and political decision-makers regarding their efficacy $(2,15,16)$.

In parallel with the imposed restrictions to prevent viral spread and the testing of (mainly) repurposed anti-viral treatments is the accelerated development of vaccines to prevent/restrict potential viral damage. Questions have been raised as to whether an accelerated vaccine development can be accomplished safely, preventing potential adverse vaccine effects not only in the short-term, but also in the mid- and long-term (https://smartech.gatech.edu/handle/1853/63710).

Currently (mid-September, 2020), there is avid competition regarding the development and commercialization of a vaccine by early $2021(17,18)$. One candidate vaccine, Sputnik-5, was approved by the Ministry of Health of the Russian Federation on August 11, 2020 (18). These accelerated vaccine development efforts suggest that safety testing was performed in $\leq 1$ year, a time frame significantly shorter than that of 12-15 years typically associated with the commercialization of a vaccine (19). It is difficult to see how mid- and long-term safety testing for the proposed vaccine (or any vaccine or drug) can be performed credibly in such a compressed time frame (https://smartech.gatech.edu/handle/1853/63710) for reasons described below.

\section{Vaccine safety testing}

There are three ways of testing for vaccine safety, in order of increasing credibility: Computer simulations, animal experiments and human trials.

Computer simulations. While the growth of statistical software packages and chemical descriptors allows the development of new models, safeguards that account for deficiencies of 
the underlying models may be lacking. This could impact the credibility of any conclusions on safety or toxicity (20). Thus, while these models may provide interesting insight, they cannot substitute for human trials, at least at this point in their development.

Animal experimentation. There are several examples where whole animal experiments have been poor predictors of human responses to environmental exposures or drugs. Isotretinoin (acutane), for example, has been demonstrated to cause birth defects in rabbits, monkeys and humans, but not in mice or rats. As another example, corticosteroids are teratogenic in experimental animals, but not in humans. In addition, there is the well-known example of Thalidomide, 'a teratogen in humans, but not in many experimental animal species' (20).

Why are some animal experiments poor predictors of human outcomes and responses? The studies may be designed poorly and may be inadequate methodologically; the studies may not be replicated or subject to meta-analyses; the metabolic pathways or drug metabolism of humans differ from those of the tested species or strains and 'disease manifestations in the animals are distinct from those encountered in humans' (20).

Laboratory animal experiments allow for the selection of test animals with short lifetimes, and can identify adverse health effects over the animals' lifetimes (the analog of long-term human effects), and perhaps one or two generations beyond. As previously stated (20), how well the response of the species selected for the experiments reflects the response of humans remains to be determined.

Additionally, laboratory animals are typically exposed to one toxic stressor (vaccines, in the present case), whereas human beings are exposed to myriad toxic stressors daily and over their lifetimes (21-24). These toxic stressor exposures may substantially alter the effects of a vaccine (25). To simulate the human real-life experience, a number of animal experiments would have to be performed to reflect the effects of various combinations of the thousands of toxic stressors (in conjunction with vaccines) to which human beings could be exposed (and other exposures that, by themselves are not toxic, but in combination are toxic) (26-33). These experiments would require vast amounts of resources, particularly money and time.

Human clinical trials. Human trials have at least two advantages over laboratory animal experiments. First, there are no concerns regarding species differences that occur when extrapolating from laboratory animal testing results to potential human impacts. Second, humans are exposed to myriad toxic stressors before, during and after the trial period, providing results that mirror the real-life experience. In all cases, human trials will be most relevant if the characteristics of the trial population reflect those of the target/user population.

The disadvantages of human clinical trials are as follows: i) The exposures to toxic stimuli are either not known, or, if they are known, have not been estimated accurately; and ii) the identification of the long-term effects requires long periods of time (https://smartech.gatech.edu/handle/1853/63710). How much time is required? In a previous study of vaccines and autoimmunity (34), the authors concluded that 'latency periods can range from days to years for postinfection and postvaccination autoimmunity'. Mid-term adverse effects of vaccines, such as central nervous system (CNS) inflammatory demyelination (35) and diabetes (36) have been shown to emerge after approximately 3 years. Longer-term effects, such as cancer, Alzheimer's disease, Parkinson's disease, etc., have not been studied. In fact, vaccine inserts typically state that carcinogenic effects (and mutagenic and fertility effects) have not been studied (37) [e.g., for the MMR vaccine it is stated that 'M-M-R II has not been evaluated for carcinogenic or mutagenic potential, or potential to impair fertility ... Animal reproduction studies have not been conducted with M-M-R II'; and for the HPV vaccine it is stated that 'GARDASIL 9 has not been evaluated for the potential to cause carcinogenicity, genotoxicity or impairment of male fertility' (37)]. Several decades of close tracking would be required to identify such adverse effects.

An overlooked issue associated with the vaccine discussions is potential transgenerational effects. Transgenerational studies of adverse substance effects tend to be focused on environmental causes; however, there are some examples of such studies for drugs. A previous study on chemotherapy-induced late transgenerational effects (38) has raised some concerns, both due to the scarcity of such studies in the literature and the transmission of adverse effects deep in the generational chain.

Due to the inadequate safety testing of several toxic stimuli in the past (including vaccines), it remains uncertain as to whether a number of diseases currently affecting humanity may be due in part to the actions of our predecessors passed on to us through transgenerational effects. It is uncertain as to whether any of the drugs, vaccines, foods or radiation exposures of our predecessors, which were not tested for transgenerational effects, are adversely affecting human life at present. Of note, the question remains whether humanity is currently willing to pass on potential devastating diseases to future generations due to the present need for the speedy development of a vaccine, bypassing adequate long-term and transgenerational safety testing.

There are also ethical issues of concern associated with accelerated vaccine development, particularly with the drastic reduction in time devoted to clinical trial phases II and III (39). The main target population for a vaccine is the most vulnerable demographically: the elderly with high comorbidities and dysfunctional immune systems. Yet, the test demographic population being used for the initial clinical trials is the relatively young and healthy population (as discussed below). This leads to uncertainty regarding the efficacy of the trial, raising issues as to how the results from a young healthy population can be extrapolated to an elderly and vulnerable population. Additionally, in myriad cultures, it is the elderly who sacrifice for the benefit of the young. This tradition is being inverted in the present accelerated testing regimen.

\section{Cost-benefit tradeoffs}

For any new product, the decision to implement (whether for commercial or non-commercial purposes) typically involves a tradeoff between costs and benefits. In the ideal case, the projected benefits would far outweigh the projected costs. The 
potential costs and/or benefits may be known to high, modest, or low degrees of certainty. Thus, a risk factor must be applied to the costs and benefits, reflecting the level of uncertainty about the projections.

The vaccine costs in this discussion are the potential adverse health effects from a COVID-19 vaccine, particularly for the mid- and long-term. For a vaccine with high levels of uncertainty as to the projected costs, a high risk factor is required. For the tradeoff to justify moving forward, a very high level of benefits would be required.

The cost-benefit tradeoff for a COVID-19 vaccine would be different for groups with different vulnerabilities to the disease. For simplicity, the target population for vaccination could be divided into 2 groups: The highly vulnerable, and the remainder of the population. The demographic population most vulnerable to the more severe consequences of COVID-19 tends to be the elderly with high comorbidities and others with compromised immune systems (2). It is a small fraction of the total population, although a somewhat greater fraction of the senior population. The remainder of the population, when infected with the SARS-CoV-2 virus, usually displays no symptoms or minimal symptoms. This demographic sub-division is similar to that for influenza and for the 2002 SARS pandemic (40).

The vaccine tradeoff analysis will differ for each of these two groups. For the most vulnerable, the main consideration is to survive the season. The mid- and long-term effects may be of lesser importance (although for the few younger members of this demographic population with highly compromised immune systems, the mid- and long-term adverse effects would not be negligible). For the least vulnerable (the vast majority of the population), the need for a vaccine is unclear, since the adverse effects of the virus appear to be minimal for most. This least vulnerable demographic population would have to bear the brunt of any potential mid- and long-term adverse health impacts that may result from a vaccine inadequately tested for these effects.

Thus, a vaccine that proved efficacious for the very short-term for all demographics may potentially be justifiable (albeit high-risk) for the most vulnerable demographic population. However, it is difficult to ascertain how such a vaccine could be justified for the remaining demographics.

Furthermore, the question remains of what are the present prospects for a vaccine efficacious even in the short-term. Trial results for a highly-promoted COVID-19 vaccine reported publicly have exhibited adverse effects of varying severity, where the test group was relatively young and very healthy $(41,42)$, unlike the highly vulnerable elderly target group with comorbidities. In other words, even short-term efficacy has not yet been demonstrated for the least vulnerable demographic population, much less the most vulnerable demographic population who would be the most justifiable target of the vaccine.

In the present political environment, there is the potential that the majority of the population could be required to be vaccinated, even those demographics that were not vulnerable to the severe effects of COVID-19, and particularly those in the youngest demographic. The potential adverse consequences of such a mass inoculation with a vaccine not adequately tested for mid- and long-term adverse effects could be substantial.

\section{Acknowledgements}

Not applicable.

\section{Funding}

No funding was received.

\section{Availability of data and materials}

Not applicable.

\section{Authors' contributions}

All authors substantially contributed to the conception, writing and revision of the work and approved the final content of the manuscript.

\section{Ethics approval and consent to participate}

Not applicable.

\section{Patient consent for publication}

Not applicable.

\section{Competing interests}

DAS is the Editor-in-Chief for the journal, but had no personal involvement in the reviewing process, or any influence in terms of adjudicating on the final decision, for this article. The other authors declare that they have no competing interests.

\section{References}

1. Docea AO, Tsatsakis A, Albulescu D, Cristea O, Zlatian O, Vinceti M, Moschos SA, Tsoukalas D, Goumenou M, Drakoulis N,et al: A new threat from an old enemy: Re-emergence of coronavirus (Review). Int J Mol Med 45: 1631-1643, 2020.

2. Kostoff RN, Briggs MB, Porter AL, Aschner M, Spandidos DA and Tsatsakis A: [Editorial] COVID-19: Post-lockdown guidelines. Int J Mol Med 46: 463-466, 2020.

3. Goumenou M, Sarigiannis D, Tsatsakis A, Anesti O, Docea AO, Petrakis D, Tsoukalas D, Kostoff R, Rakitskii V, Spandidos DA, et al: COVID-19 in Northern Italy: An integrative overview of factors possibly influencing the sharp increase of the outbreak (Review). Mol Med Rep 22: 20-32, 2020.

4. Kostoff RN, Briggs MB, Porter AL, Hernández AF, Abdollahi M, Aschner $\mathrm{M}$ and Tsatsakis A: The under-reported role of toxic substance exposures in the COVID-19 pandemic. Food Chem Toxicol 145: 111687, 2020.

5. Farsalinos K, Niaura R, Le Houezec J, Barbouni A, Tsatsakis A, Kouretas D, Vantarakis A and Poulas K: Editorial: Nicotine and SARS-CoV-2: COVID-19 may be a disease of the nicotinic cholinergic system. Toxicol Rep 7: 658-663, 2020.

6. Skalny AV, Rink L, Ajsuvakova OP, Aschner M, Gritsenko VA, Alekseenko SI, Svistunov AA, Petrakis D, Spandidos DA, Aaseth J, et al: Zinc and respiratory tract infections: Perspectives for COVID-19 (Review). Int J Mol Med 46: 17-26, 2020.

7. Nitulescu GM, Paunescu H, Moschos SA, Petrakis D, Nitulescu G, Ion GND, Spandidos DA, Nikolouzakis TK, Drakoulis $\mathrm{N}$ and Tsatsakis A: Comprehensive analysis of drugs to treat SARS-CoV-2 infection: Mechanistic insights into current COVID-19 therapies (Review). Int J Mol Med 46: 467-488, 2020.

8. Stancioiu F, Papadakis GZ, Kteniadakis S, Izotov BN, Coleman MD, Spandidos DA and Tsatsakis A: A dissection of SARS-CoV2 with clinical implications (Review). Int J Mol Med 46: 489-508, 2020. 
9. Torequl Islam M, Nasiruddin M, Khan IN, Mishra SK, Kudrat-E-Zahan M, Alam Riaz T, Ali ES, Rahman MS, Mubarak MS, Martorell M, et al: A perspective on emerging therapeutic interventions for COVID-19. Front Public Health 8: $281,2020$.

10. Arsene AL, Dumitrescu IB, Dragoi CM, Udeanu DI, Lupuliasa D, Jinga V, Draganescu D, Dinu-Pirvu CE, Dragomiroiu G, Blejan IE, et al: A new era for the therapeutic management of the ongoing Covid-19 pandemic. Farmacia 68: 185-196, 2020.

11. Dehelean CA, Lazureanu V, Coricovac D, Mioc M, Oancea R, Marcovici I, Pinzaru I, Soica C, Tsatsakis AM and Cretu O SARS-CoV-2: Repurposed drugs and novel therapeutic approaches - insights into chemical structure-biological activity and toxicological screening. J Clin Med 9: 2084, 2020.

12. Teslya A, Pham TM, Godijk NG, Kretzschmar ME, Bootsma MCJ and Rozhnova G: Impact of self-imposed prevention measures and short-term government-imposed social distancing on mitigating and delaying a COVID-19 epidemic: A modelling study. PLoS Med 17: e1003166, 2020.

13. Nazarenko Y: Air filtration and SARS-CoV-2. Epidemiol Health 42: e2020049, 2020

14. Fathizadeh H, Maroufi P, Momen-Heravi M, Dao S, Köse Ş, Ganbarov K, Pagliano P, Esposito S and Kafil HS: Protection and disinfection policies against SARS-CoV-2 (COVID-19). Infez Med 28: 185-191, 2020.

15. Li Y, Tokura H, Guo YP, Wong AS, Wong T, Chung $\mathrm{J}$ and Newton E: Effects of wearing N95 and surgical facemasks on heart rate, thermal stress and subjective sensations. Int Arch Occup Environ Health 78: 501-509, 2005.

16. Lazzarino AI, Steptoe A, Hamer M and Michie S: Covid-19: Important potential side effects of wearing face masks that we should bear in mind. BMJ 369: m2003, 2020.

17. HHS.gov: Fact Sheet: Explaining Operation Warp Speed. https://www.hhs.gov/about/news/2020/06/16/fact-sheet-explainingoperation-warp-speed.html. Accessed June 16, 2020.

18. Craven J: COVID-19 vaccine tracker. Regulatory Affairs Professionals Society, Rockville, MD, 2020. https://www.raps.org/ news-and-articles/news-articles/2020/3/covid-19-vaccine-tracker. Accessed September 10, 2020.

19. Calina D, Docea AO, Petrakis D, Egorov AM, Ishmukhametov AA, Gabibov AG, Shtilman MI, Kostoff RN, Carvalho F, Vinceti M, et al: Towards effective COVID-19 vaccines: Updates, perspectives and challenges (Review). Int J Mol Med 46: 3-16, 2020.

20. Aschner M: Are we rushing too much? Food Chem Toxicol 143 111551,2020

21. Kostoff RN, Goumenou M and Tsatsakis A: The role of toxic stimuli combinations in determining safe exposure limits. Toxicol Rep 5: 1169-1172, 2018.

22. Tsatsakis A, Petrakis D, Nikolouzakis TK, Docea AO, Calina D, Vinceti M, Goumenou M, Kostoff RN, Mamoulakis C, Aschner M and Hernández AF: COVID-19, an opportunity to reevaluate the correlation between long-term effects of anthropogenic pollutants on viral epidemic/pandemic events and prevalence. Food Chem Toxicol 141: 111418, 2020.

23. Hernández AF and Tsatsakis AM: Human exposure to chemical mixtures: Challenges for the integration of toxicology with epidemiology data in risk assessment. Food Chem Toxicol 103: 188-193, 2017.

24. Tsatsakis AM, Kouretas D, Tzatzarakis MN, Stivaktakis P, Tsarouhas K, Golokhvast KS, Rakitskii VN, Tutelyan VA, Hernandez AF, Rezaee R, et al: Simulating real-life exposures to uncover possible risks to human health: A proposed consensus for a novel methodological approach. Hum Exp Toxicol 36: 554-564, 2017

25. Tsatsakis AM, Docea AO and Tsitsimpikou C: New challenges in risk assessment of chemicals when simulating real exposure scenarios; simultaneous multi-chemicals' low dose exposure. Food Chem Toxicol 96: 174-176, 2016

26. Benn CS, Netea MG, Selin LK and Aaby P: A small jab - a big effect: Nonspecific immunomodulation by vaccines. Trends Immunol 34: 431-439, 2013.

27. Kostoff RN, Aschner M, Goumenou M and Tsatsakis A: Setting safer exposure limits for toxic substance combinations. Food Chem Toxicol 140: 111346, 2020.
28. Sergievich AA, Khoroshikh PP, Artemenko AF,Zakharenko AM, Chaika VV, Kodintsev VV, Stroeva OA, Lenda EG, Tsatsakis A, Burykina TI, et al: Behavioral impacts of a mixture of six pesticides on rats. Sci Total Environ 727: 138491, 2020.

29. Fountoucidou P, Veskoukis AS, Kerasioti E, Docea AO, Taitzoglou IA, Liesivuori J, Tsatsakis A and Kouretas D: A mixture of routinely encountered xenobiotics induces both redox adaptations and perturbations in blood and tissues of rats after a long-term low-dose exposure regimen: The time and dose issue. Toxicol Lett 317: 24-44, 2019.

30. Tsatsakis A, Docea AO, Constantin C, Calina D, Zlatian O, Nikolouzakis TK, Stivaktakis PD, Kalogeraki A, Liesivuori J, Tzanakakis G, et al: Genotoxic, cytotoxic, and cytopathological effects in rats exposed for 18 months to a mixture of 13 chemicals in doses below NOAEL levels. Toxicol Lett 316: 154-170, 2019.

31. Tsatsakis A, Tyshko NV, Docea AO, Shestakova SI, Sidorova YS, Petrov NA, Zlatian O, Mach M, Hartung T and Tutelyan VA The effect of chronic vitamin deficiency and long term very low dose exposure to 6 pesticides mixture on neurological outcomes - A real-life risk simulation approach. Toxicol Lett 315 96-106, 2019.

32. Docea AO, Gofita E, Goumenou M, Calina D, Rogoveanu O, Varut M, Olaru C, Kerasioti E, Fountoucidou P, Taitzoglou I, et al: Six months exposure to a real life mixture of 13 chemicals' below individual NOAELs induced non monotonic sex-dependent biochemical and redox status changes in rats. Food Chem Toxicol 115: 470-481, 2018.

33. Docea AO, Goumenou M, Calina D, Arsene AL, Dragoi CM, Gofita E, Pisoschi CG, Zlatian O, Stivaktakis PD, Nikolouzakis TK, et al: Adverse and hormetic effects in rats exposed for 12 months to low dose mixture of 13 chemicals: RLRS part III. Toxicol Lett 310: 70-91, 2019.

34. Tsatsakis AM, Docea AO, Calina D, Buga AM, Zlatian O, Gutnikov S, Kostoff RN and Aschner M: Hormetic neurobehavioral effects of low dose toxic chemical mixtures in real-life risk simulation (RLRS) in rats. Food Chem Toxicol 125: 141-149, 2019.

35. Agmon-Levin N, Paz Z, Israeli E and Shoenfeld Y: Vaccines and autoimmunity. Nat Rev Rheumatol 5: 648-652, 2009.

36. Mikaeloff Y, Caridade G, Suissa S and Tardieu M: Hepatitis B vaccine and the risk of CNS inflammatory demyelination in childhood. Neurology 72: 873-880, 2009.

37. Classen JB and Classen DC: Clustering of cases of insulin dependent diabetes (IDDM) occurring three years after hemophilus influenza B (HiB) immunization support causal relationship between immunization and IDDM. Autoimmunity 35 247-253, 2002

38. Institute for Vaccine Safety, Johns Hopkins Bloomberg School of Public Health: Package inserts and manufacturers for some US licensed vaccines and immunoglobulins. https://www.vaccinesafety.edu/package inserts.htm. Last update June 30, 2020.

39. Kostoff RN: Under-reporting of Adverse Events in the Biomedical Literature. J Data Inf Sci 1: 10-32, 2017

40. Calina D, Hartung T, Docea AO, Spandidos DA, Egorov AM, Shtilman MI, Carvalho F and Tsatsakis A: COVID-19 vaccines: Ethical framework concerning human challenge studies. Daru: Aug 27, 2020 (Epub ahead of print).

41. Maragakis LL: Coronavirus Disease: 2019 vs. the Flu. Johns Hopkins Medicine, 2020. https://www.hopkinsmedicine.org/ health/conditions-and-diseases/coronavirus/coronavirus-disease2019-vs-the-flu. Updated September 16, 2020.

42. Jackson LA, Anderson EJ, Rouphael NG, Roberts PC, Makhene M, Coler RN, McCullough MP, Chappell JD, Denison MR, Stevens LJ, et al; An mRNA vaccine against SARS-CoV-2 - preliminary report. N Engl J Med: Jul 14, 2020 (Epub ahead of print).

This work is licensed under a Creative Commons Attribution-NonCommercial-NoDerivatives 4.0 International (CC BY-NC-ND 4.0) License. 